Competitive Equilibrium with Middlemen: An Empirical Study

Author(s): Charles R. Plott and Jonathan T. Uhl

Source: Southern Economic Journal, Vol. 47, No. 4 (Apr., 1981), pp. 1063-1071

Published by: Southern Economic Association

Stable URL: http://www.jstor.org/stable/1058163

Accessed: 20/02/2014 14:12

Your use of the JSTOR archive indicates your acceptance of the Terms \& Conditions of Use, available at http://www.jstor.org/page/info/about/policies/terms.jsp

JSTOR is a not-for-profit service that helps scholars, researchers, and students discover, use, and build upon a wide range of content in a trusted digital archive. We use information technology and tools to increase productivity and facilitate new forms of scholarship. For more information about JSTOR, please contact support@ jstor.org. 


\section{Competitive Equilibrium with Middlemen: An Empirical Study*}

\section{Introduction}

Public distrust of middlemen frequently occurs in market systems. Boycotts, regulations, and investigations of middlemen are not uncommon [3; 7]. This position of disfavor is somewhat paradoxical since application of economic theory suggests that competition among middlemen can be relied upon to protect consumers and producers. According to received doctrine any differences in purchase and resale prices would reflect the costs involved in market making. Nevertheless public suspicion remains.

While the reason for public suspicion is never precisely stated, it seems to be based upon the obvious special position that middlemen occupy. By holding purchase prices low and resale prices high, by simply restricting carry-forward, middlemen will profit. This possibility is certainly obvious to everyone and in particular it is obvious to the middlemen themselves. Consequently, unlike many other markets the potential gain from cooperation and the joint cooperative strategy is clear to all. Because of this special environment markets with middlemen may have an inherent tendency to behave differently when compared to other markets.

Aside from this "natural coalitional situation" for some participants, markets with middlemen are also characterized by a type of informational asymmetry. Primary producers are generally unaware of the final market demand and prices for their product. They see this demand only as filtered through the middlemen. Likewise, ultimate consumers receive the offers of producers attempting to sell their produce only as filtered through the middlemen. Thus with the establishment of middlemen a single market containing primary producers and ultimate consumers is partitioned into two markets: primary producers and middlemen plus final consumers and middlemen. The competitive theory applied without sensitivity to the informational differences predicts that the two markets will behave as the one.

Because of the informational asymmetry the study of markets with middlemen provides a particularly good opportunity to further isolate conditions under which the competitive model tends to work. It is now well established by many replications that in stationary markets organized under auction rules contracts prices tend to converge to or deviate only slightly from the theoretical equilibrium. The phenomenon occurs even though participants know only their own individual supply or demand schedule. Miller, Plott, and Smith [2] have suggested that necessary and sufficient conditions for a classical competitive stationary equilibrium include the following: (1) each economic agent knows only his own valuation conditions, (2) information on all price bids, price offers, and price contracts is available at approximately zero cost to all agents, and (3) the process is repetitively stationary, i.e., each

* Financial support provided by the National Science Foundation and by the Caltech Program for Enterprise and Public Policy is gratefully acknowledged. 
agent is a buyer or a seller of units in each of several trading periods with individual valuations unchanging from period to period. This permits learning by trial and error from one trading period to the next.

This experiment is based on the idea that a stationary market which yields a competitive equilibrium with buyers and sellers interacting directly will also yield a competitive equilibrium when middlemen are placed between the ultimate buyers and primary sellers. Since only the middlemen are familiar with information on prices in both markets, and since the only market information exchanged between the two markets is that conveyed by the actions of the middlemen, condition (2) is violated. Nevertheless, we hypothesize that the average contract price in the middlemen/primary sellers and middlemen/ultimate buyers markets will deviate only slightly, if at all, in the final trading period. In addition, the competitive price/quantity equilibrium will be reached in the final trading period.

The trading institution used in the markets we study here differs slightly from the organization used in previous studies. In all other double oral auctions only one outstanding bid or offer existed at a time. Each bid or offer canceled any previous bid or offer. ${ }^{1}$ In the markets studied here all bids and offers remained active until changed, retracted by the individual making them, or accepted. Thus our markets are similar to markets in which limit orders can be placed in an open book.

A third potentially important variable also exists. In one experimental market (market $X$ ), four middlemen existed and for a second experimental market (market $Y$ ), three middlemen existed. This is a potentially important departure from the Miller, Plott, Smith [2] study in which only two traders existed. Intuitively it seems as though three or four traders may accidentally carry forward "too much" or "too little"; with many traders no one has good information about the total planned carry-forward of the group.

\section{Subjects and Experimental Design}

The subjects were undergraduate male and female students at the California Institute of Technology. They were recruited by asking for volunteers in the lounges of the student houses. Subjects were divided into four groups: buyers, sellers, traders $X$, and traders $Y$, and placed in four separate rooms. In these experiments the middlemen were termed "traders." The individual marginal supply and demand valuations were assigned randomly to the sellers and buyers respectively who were spatially seated so that this individual information was private. In each separate room copies of the instructions, similar to those used in Miller, Plott, Smith [2], were distributed and read aloud by one of the experimenters, after which questions were answered. So not only were parameters known only individually, participants did not know the instructions given to any other group.

In this experiment there were two separate markets, an $X$ market and a $Y$ market. In the $X$ market, traders $X$ purchased units of commodity $X$ from the sellers during the buying season for sale to the buyers during the selling season. In the $Y$ market, traders $Y$ purchased units of commodity $Y$ from the sellers during the buying season for sale to the buyers during the selling season. The markets were executed in an alternating sequence with only one commodity being traded each period. Thus sellers first sold $X$ to traders $X$ in room 1 and then, while traders $X$ were reselling $X$ to buyers in room 2, the sellers in room 1 were selling $Y$ to traders $Y$. Traders could hold units for only one season with zero storage cost, and short sales

1. Under some rules a bid (offer) must be higher (lower) than the outstanding bid (offer) on the floor in order to replace it on the floor. 
were not permited. This corresponds to a crop commodity that is perishable by the end of season. At no time was any information exchanged directly between the sellers and buyers or between traders $X$ and traders $Y$. As traders moved between rooms, they were accompanied at all times by some member of the experimental team.

The demand and supply schedules shown in Figures 1 and were constructed in accordance with the theory of induced valuation [6]. For example, from Figure 1, subject 5 (a seller had marginal costs of $\$ 1.18$ for his first unit, $\$ 1.39$ for a second unit, and $\$ 1.60, \$ 1.98, \$ 2.34$, and $\$ 2.42$ for this third through sixth unit respectively in the $X$ market. Similarly, in the $Y$ market his marginal costs were $\$ 2.76, \$ 3.10, \$ 3.24$, and $\$ 3.67$. Each seller received cash payments equal to $\$ 0.10$ plus the difference between the sales price and the marginal cost for each sold. Each buyer received cash payments equal to $\$ 0.10$ plus the difference between the marginal valuation and purchase price for each unit bought. Each trader received $\$ 0.10$ plus the difference between the selling price and buying price for each unit traded. The purpose of the 10 cent "commission" was to overcome subjective transaction cost and thereby to induce minimally the exchange of marginal units by a buyer, seller, or trader [4]. Traders each received $\$ 1$ per period in starting capital to cover potential losses.

Market demand in both markets was obtained from the demands of five buyers, while market supply was derived from the supplies of five sellers. Four subjects served as traders in the $X$ market where the competitive price-quantity equilibria were $\$ 1.67$ and fourteen units. Similarly, the $Y$ market had three traders and the competitive price-quantity equilibria were $\$ 3.10$ and nine units. No trader had knowledge of the valuations of any buyer or seller, nor were traders explicitly informed of each other's inventory.

\section{Experimental Results}

Figures 3 and 4 show the tendency of contract prices in successive trading periods to converge to values near the competitive equilibrium price. Early periods show low prices due to middleman caution. At the start of the experiment when middlemen face primary sellers for the first time they have no idea of what demand will be in the middlemen/ultimate buyer market. This caution is understandable. However, after experience has been gained by the middleman, the markets converge to near the competitive equilibrium. In the $X$ market (Figure 3), the buying and selling prices in the final trading period are $\$ 1.6707$ and $\$ 1.6857$ respectively with fourteen units traded. The equilibrium price and quantity is $\$ 1.67$ and fourteen units. In the $Y$ market (Figure 4), the buying and selling prices in the final trading period are $\$ 3.1625$ and $\$ 3.0863$ with eight units traded. The equilibrium price and quantity are $\$ 3.10$ and nine units.

Table I shows that middlemen profits tended to decrease in successive trading periods. In fact, the middlemen in the $Y$ market actually had negative profits in the last two trading periods.

An alternative measure of market performance is obtained by computing the index of efficiency [4, 139-42]. Inefficiencies occur when extramarginal units (units with marginal supply valuations above and units with marginal demand valuations below the equilibrium price) are traded and when intramarginal units (with marginal supply valuations below, and marginal demand valuations above the equilibrium) fail to be traded. No inefficiency occurs if and only if subjects receive the maximum total payments (consumer plus producer sur- 
1066 COMMUNICATIONS

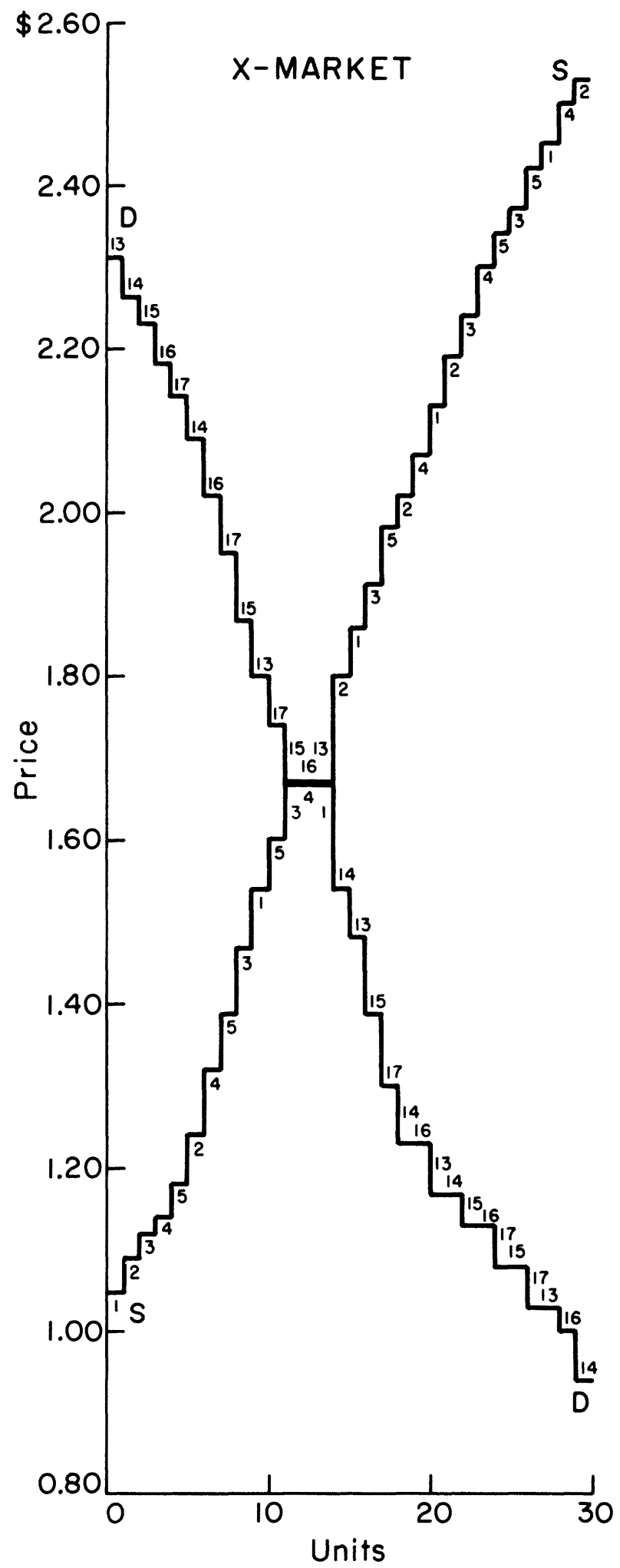

Figure 1. Induced Supply and Demand Curve 


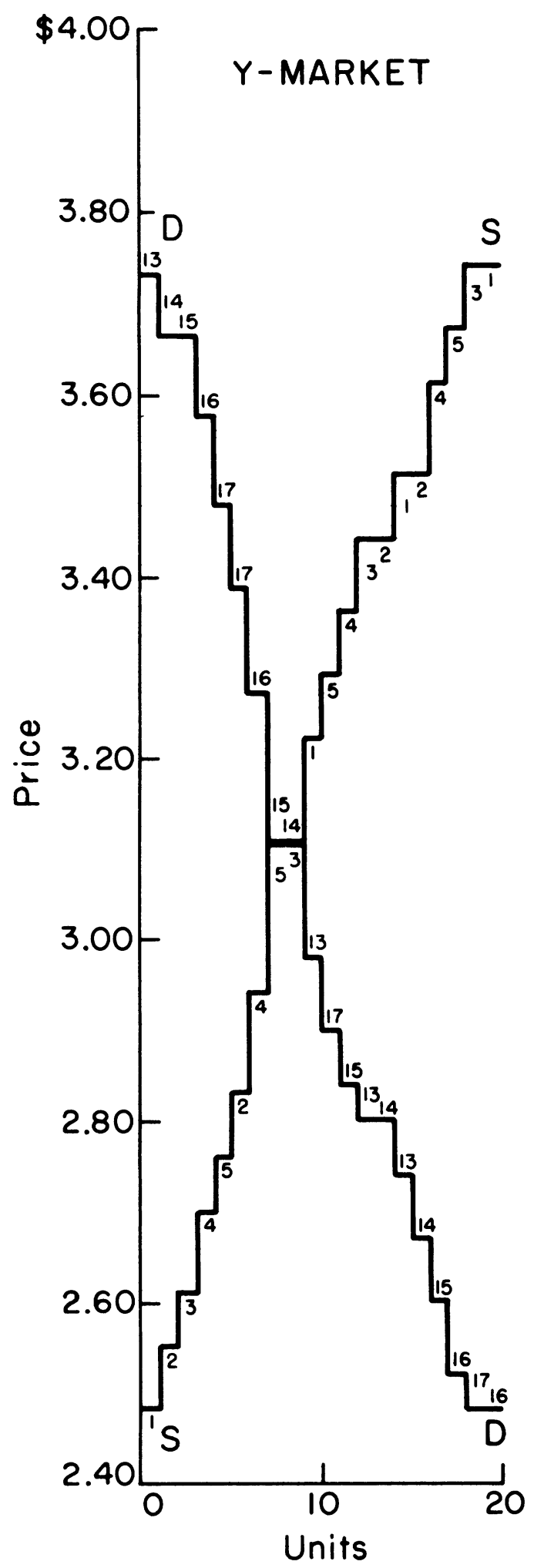

Figure 2. Induced Supply and Demand Curve 
1068 COMMUNICATIONS

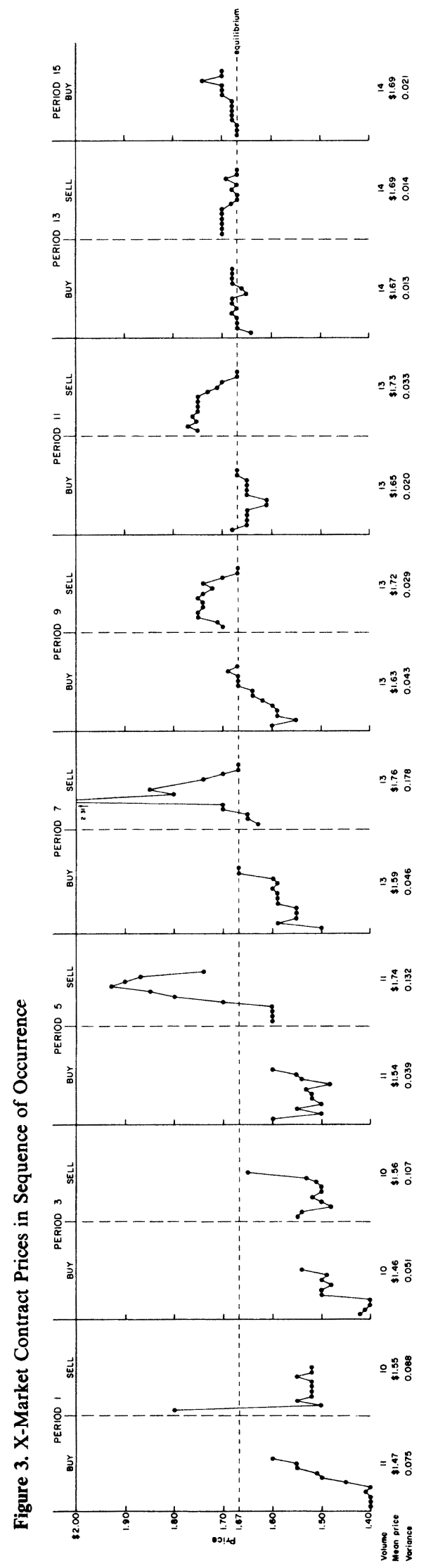




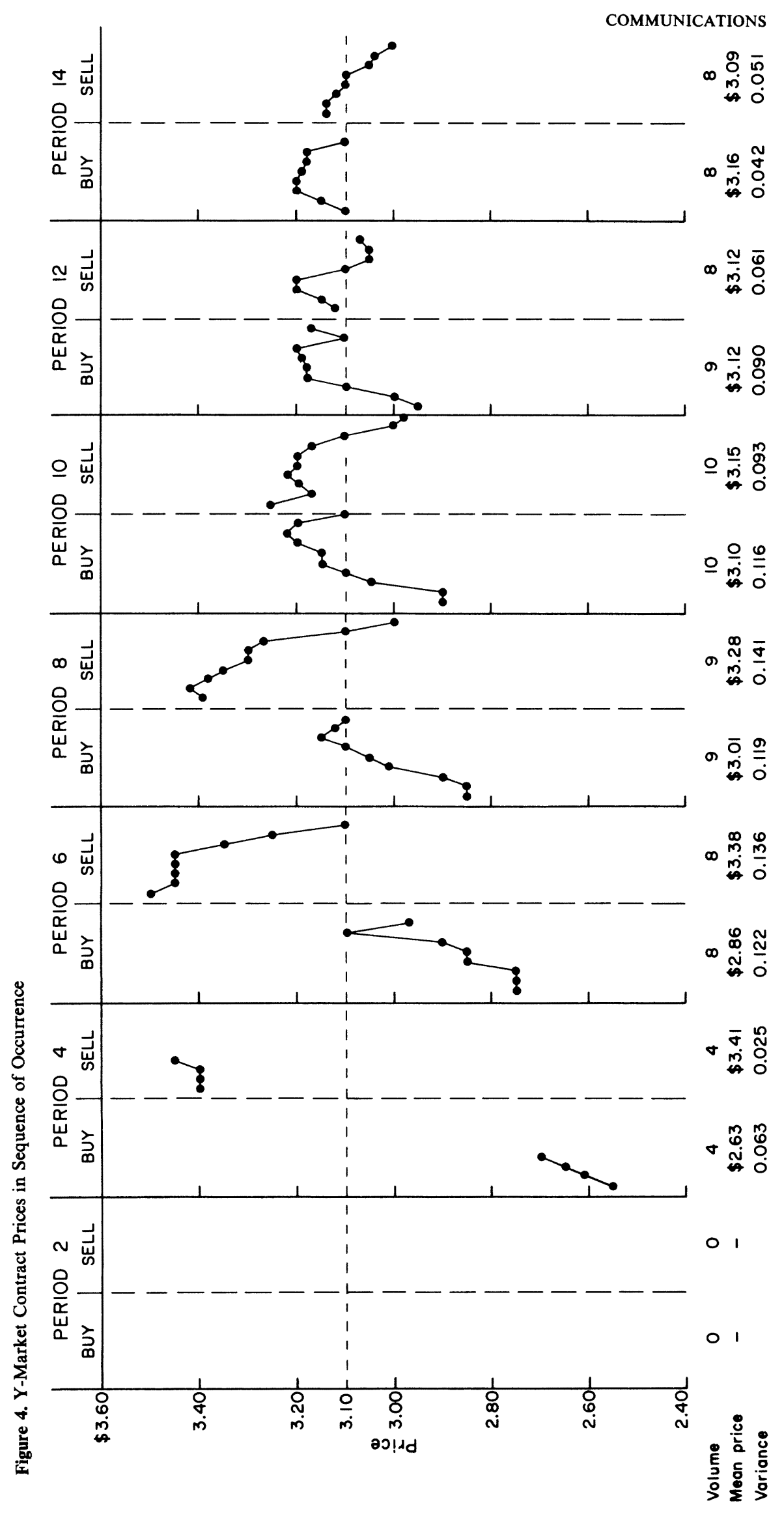


Table I. Middleman Profits Excluding Commissions and Capital Payments

\begin{tabular}{lccccccc}
\hline Period & 1 & 3 & 5 & 7 & 9 & 11 & 13 \\
Traders X (\$) & 0.95 & 0.64 & 2.30 & 2.20 & 1.18 & 1.07 & 0.21 \\
\hline Period & 2 & 4 & 6 & 8 & 10 & 12 & 14 \\
Traders Y (\$) & 0.00 & 0.14 & 4.10 & 2.38 & 0.52 & -3.13 & -0.51 \\
\hline
\end{tabular}

plus). Actual payments as a percentage of the maximum available under perfect competitive price equilibrium ( $\$ 12.65$ per period in the $X$ market, and $\$ 8.60$ per period in the $Y$ market) provide an index of efficiency shown in Table II.

The efficiency in the later periods is comparable to that obtained in similar experiments without middlemen [5] with one exception. In period 6 of the $Y$ market, one middleman mistakenly did not sell a unit purchased due to inaccurate bookkeeping. If this unit is neglected, the efficiency would be 98.5 percent for that period.

\section{Conclusions}

Competitive forces among middlemen in the two markets we studied effectively prevented profiteering at the expense of producers and consumers. The behavior of these markets is well within the range of experience with experimental markets in general and markets with speculators in particular $[2 ; 1]$ and it is approximated by the competitive model.

The predictions of the loose theories about the pervasive influence of middlemen upon which these experiments were based have failed to materialize. Perhaps within other institutional arrangements the "profiteering" advantages of middlemen can be easily seen, but currently it is not obvious that such arrangements exist. Those who feel that the special position of the middleman as an agent which separates ultimate consumers from primary producers necessarily leads to a type of monopoly rents are wrong in the sense that if such effects exist they are sufficiently small so that they will be detected only after many observations. The ad-

Table II. Index of Efficiency

\begin{tabular}{lrrrrrrr}
\hline Period & 1 & 3 & 5 & 7 & 9 & 11 & 13 \\
X Market (\%) & 87.4 & 81.4 & 91.3 & 97.4 & 97.6 & 97.6 & 100.0 \\
\hline Period & 2 & 4 & 6 & 8 & 10 & 12 & 14 \\
Y Market (\%) & 00.0 & 60.9 & 96.5 & 100.0 & 100.0 & 61.6 & 93.4 \\
\hline
\end{tabular}


dition of one set of middlemen between consumers and producers does not automatically lead to "substantial" market inefficiencies. In fact, we could detect none at all. In order for further experiments to be useful, those suspicious of middlemen should refine the theory in a way which would help focus the experimental design on the study of special cases where the potential influences are magnified and easily detectable if they should exist.

The convergence to near the competitive equilibrium leads to another conclusion. Miller, Plott, Smith [2] conjecture that a necessary condition for classical competitive stationary equilibrium is that information on market prices must be available at approximately zero cost to all agents. In our experiments only the traders were fully informed. Thus, if our experimental markets are viewed as one market with middlemen carrying commodities between buyers and sellers rather than two markets, the conjecture is incorrect. Markets can converge to near the competitive equilibrium if organized "properly" even if some people are uninformed about various types of transaction prices.

The results extend the knowledge about the behavior of experimental markets in two additional directions. First, increasing the number of traders in a speculative market from two to three or four does not automatically produce instabilities. Previous research only utilized two speculators where the potential for "uncoordinated" carry-forward seemed less. Secondly, we detected no influence due to the particular trading rules. If the "open book" with limit orders behaves differently from the New York Stock Exchange rules, it may take many experimental sessions to reveal the differences. In these two experiments we found no differences which could be documented. Of course, without additional experiments we cannot conclude that these institutions (or the middlemen for that matter) have no independent effects. Yet, the results are so close to what has been observed for many experiments that the subject does not seem to be worth pursuing with further experiments until some theory suggests something specific for which we should look.

\section{Charles R. Plott California Institute of Technology Pasadena, California}

Jonathan T. Uhl Princeton University Princeton, New Jersey

\section{References}

1. Hoffman, Elizabeth and Charles R. Plott, "The Effect of Intertemporal Speculation on the Outcomes in Seller Posted Offer Auction Markets." Social Science Working Paper no. 241, California Institute of Technology, 1980. Quarterly Journal of Economics, forthcoming.

2. Miller, Ross M., Charles R. Plott, and Vernon L. Smith, "Intertemporal Competitive Equilibrium: An Empirical Study of Speculation." Quarterly Journal of Economics, November 1977, 599-624.

3. New York Times, "Middlemen Cited for Cost of Meat." Tuesday, August 31, 1976, p. 37.

4. Plott, Charles R. and Vernon L. Smith, "An Experimental Examination of Two Exchange Institutions." Review of Economic Studies, February 1978, 133-53.

5. Smith, Vernon L. "Bidding and Auctioning Institutions: Experimental Results," in Bidding and Auctioning for Procurement and Allocation, edited by Yakov Amihud. New York: New York University Press, 1976.

6. —_ "Experimental Economics: Induced Value Theory." American Economic Association Papers and Proceedings, May 1976, 274-79.

7. Tolchin, Martin, “Carter Plans Food Talks.” New York Times, August 9, 1979, p. D. 1. 